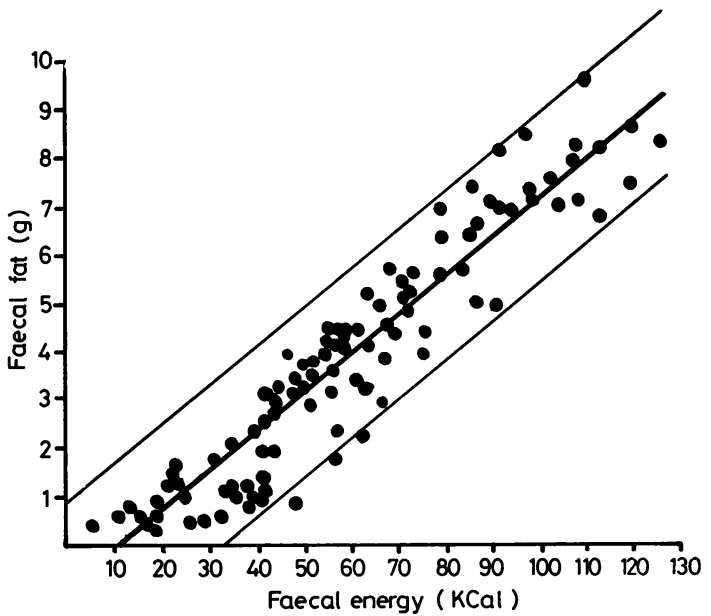

Figure Correlation between faecal fat and faecal energy in 111 24-hour stool collections from 37 preterm infants.

estimations are cumbersome and probably less accurate owing to difficulties with extraction procedures. The purpose of this investigation was to determine whether fat is indeed the major contributor to faecal energy, since calorimetry could then be used to estimate the degree of fat malabsorption.

\section{Methods}

Three-day stool collections were made in 37 preterm infants (mean birthweight $1436 \mathrm{~g}$, SD 317, gestation $32 \cdot 3$ weeks, SD 2.2). Stools were collected on polyester napkin liners (Boots) and stored frozen while awaiting analysis. Each day's collection was aggregated, weighed, freeze-dried, and homogenised with a grinder. Aliquots were then used for determination of energy by ballistic bomb calorimetry, ${ }^{1}$ and fat by a Soxhlet gravimetric method. ${ }^{4}$

\section{Results}

The figure shows the correlation between faecal fat and energy, with the $95 \%$ confidence limits. The correlation coefficient is $+0.93(\mathrm{P}<0.001)$. A given faecal energy determination will predict faecal fat to an accuracy of approximately $\pm 1 \mathrm{~g}$.

\section{Discussion}

It is apparent that fat is the major constituent of faecal energy in preterm infants and faecal fat content can be predicted with a fair degree of accuracy from faecal energy measurements. For the purposes of research faecal energy is probably more useful than faecal fat, unless fat absorption is specifically under investigation, since it provides data on the overall degree of energy malabsorption, which can then be used to calculate the difference between dietary energy and faecal losses.

\section{References}

1 Brooke O G, Alvear J, Arnold M. Energy retention, energy expenditure, and growth in healthy immature infants. Pediatr Res 1979; 13: 215-20.

2 Brooke $O$ G. Energy balance and metabolic rate in preterm infants fed with standard and high-energy formulas. Br J Nutr 1980; 44: 13-23.

3 Miller D S, Payne P R. A ballistic bomb calorimeter. Br J Nutr 1959; 13: 501-8.

4 Zuckerman J L, Zymaris M C, Natelson S. Simple method for the determination of fecal fat and fatty acids. $J$ Lab Clin Med 1949; 34: 282-6.

Correspondence to Dr O G Brooke, Department of Child Health, St George's Hospital Medical School, Cranmer Terrace, London SW17 ORE.

Received 13 January 1983

\title{
Cryptic mediastinal masses causing airways obstruction
}

\author{
D K C COOPER, A R CHRISPIN, M DE LEVAL, AND J STARK
}

Thoracic Unit, The Hospital for Sick Children, London

SUMMARY In 3 infants, severe airways obstruction was caused by mediastinal lesions which were not evident on the antero-posterior chest radiograph. Their presence was demonstrated by barium swallow examination. Each infant had thoracotomy carried out urgently. Duplication cysts (without associated cervicodorsal vertebral anomalies) were present in 2 patients and neuroblastoma in the third.
A congenital anomaly compressing the trachea or main bronchus may not be detected at an early stage, despite symptoms. There are two main reasons: (1) the history may be misleading, and (2) there may be nothing on the antero-posterior chest radiograph to suggest that the clinical and radiological features are secondary phenomena.

In cases of stridor, wheezing, or air trapping in the lung, careful scrutiny of the mediastinum for mass 


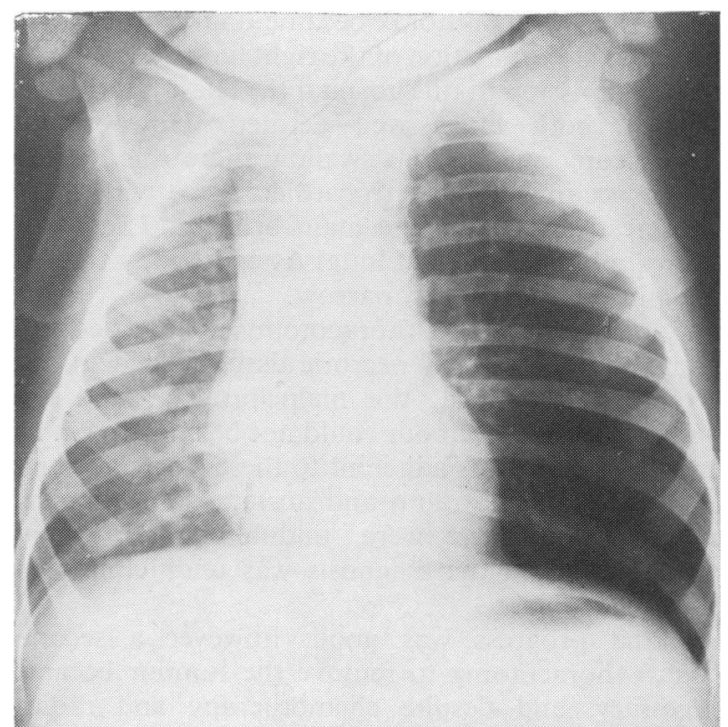

Figure (Case 1.) Chest radiograph showing increased transradiancy of the left lung, and antero-posterior and lateral chest radiographs during barium swallow showing deviation of the oesophagus posteriorly and to the right of the trachea anteriorly.
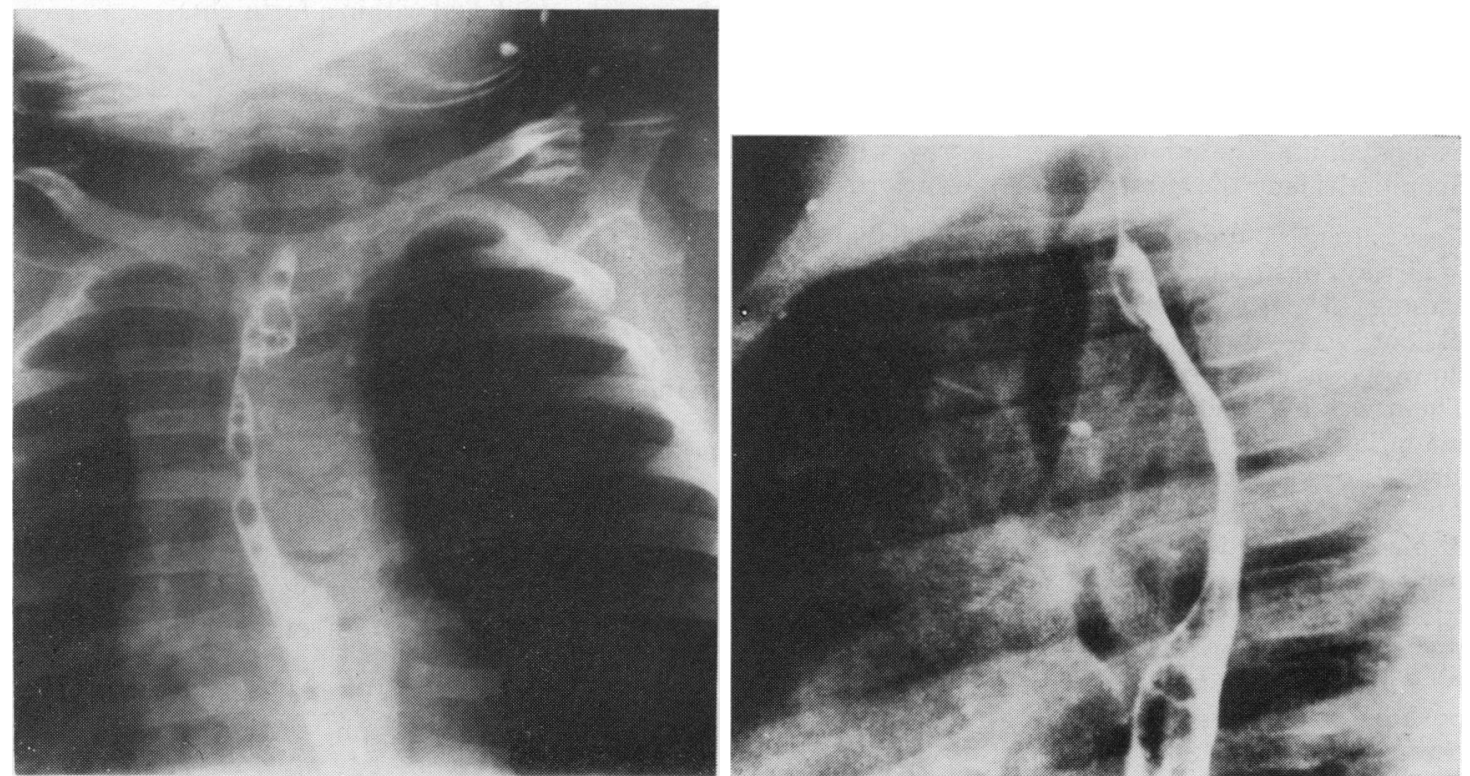

lesions, a right aortic arch, or spinal anomalies will usually lead to a barium swallow if there is any suspicion of an abnormality. If no abnormality is seen, barium swallow is often not immediately considered. This paper reports 3 infants in whom the barium swallow showed information of crucial importance. Thoracotomy led to extirpation of duplication cysts in 2 children and to the diagnosis of neuroblastoma in the third. In none of these patients

was the diagnosis obvious on either clinical findings or antero-posterior chest radiograph. One infant spent nearly 10 months in hospital and despite several complex investigations, the correct diagnosis was not established before barium swallow.

\section{Case reports}

Case 1. This 11-month-old infant was referred for 
emergency sleeve resection of her narrow left main bronchus. There was tachypnoea and severe air trapping in the left lung (Figure). Previous similar episodes with cyanosis had occurred and had precipitated admissions to other hospitals. Fluoroscopy had confirmed the air trapping, and Krypton ventilation perfusion lung scans had shown diminished perfusion and ventilation in the left lung. Narrowing of the left main bronchus had been detected at endoscopies. A bronchogram had shown, initially, no filling of the left main stem bronchus and so a fine catheter had been introduced through the bronchus to demonstrate a normal structure of the bronchial tree distally in the lung.

On admission to our unit, an immediate barium swallow showed that the oesophagus was displaced considerably to the right and posteriorly, and the lower part of the trachea was displaced forwards relative to the oesophagus, with a considerable distance between the two (Figure). A diagnosis of a cyst compressing the left main bronchus was made.

At operation the cyst compressed the left main bronchus and was adherent to the membranous part of the trachea. Twenty-four hours after operation the mediastinum was central, the lungs were well expanded, and the infant's respiration was normal. Six months later the chest $x$-ray film was normal.

Case 2. In this 4-month-old infant a clinical diagnosis of airways obstruction with cough, possibly owing to asthma of early onset, had been made. As the patient was young, a request was made for a fluoroscopic examination to assess lung ventilation. There was no localised air trapping, but when the infant lay supine on the $x$-ray table the noise of the airways obstruction seemed to be tracheal in origin. The lateral chest radiograph showed posterior displacement and some narrowing of the distal one-third of the trachea. A lateral projection at barium swallow showed an anterior impression on the oesophagus just above the level of the carina. A lateral tomograph confirmed the posterior position of the narrow trachea within the distended chest. No spinal anomaly was present but the foregut duplication cyst was removed through a right thoracotomy. The cyst lay above the right hilum and extended across the midline to the left side. Postoperative recovery was rapid and the symptoms resolved.

Case 3. This 6-week-old infant had presented at the referring hospital with wheezing, stridor, tachypnoea, and tachycardia. Air entry was diminished in the left hemithorax and a chest radiograph showed slight increase in left lung transradiancy. She was treated with antibiotics. She did not progress well; on one occasion she became apnoeic and hypoxic when the left hemithorax became uniformly opaque owing to hyperinflation of the right lung.

On admission to this hospital the chest radiograph showed both lungs well aerated. However, at fluoroscopy and barium swallow there was a mass lesion occupying the retrocardiac space with some compression of both the main bronchi. There was air trapping in the right lung. At endoscopy the left main bronchus was very narrow.

Immediately, a left thoracotomy was carried out and a mass of mainly necrotic tissue was identified around the trachea, the main bronchi, and the oesophagus. The tumour could not be removed in its entirety since it was adherent to these structures and also to the pericardium and aorta. At histological examination there were undifferentiated small round cells and the diagnosis was undifferentiated neuroblastoma.

Initial progress was good, however a second (right) thoracotomy to remove the tumour became necessary, and despite chemotherapy and radiotherapy the child died within a fortnight.

\section{Discussion}

Any infant or child who has respiratory symptoms and continuing unilateral lung transradiancy should have chest fluoroscopy and a barium swallow carried out. These procedures are simple and easy to perform. The radiation dose need not be significant by comparison with that of repeated chest radiographic studies and the result may be decisive.

The true antero-posterior and lateral projections of the barium-filled oesophagus show the relationship between the oesophagus, the trachea, and other intrathoracic structures. Each of the 3 infants had abnormal relationships. In one sense, the findings are merely an extension of the known value of the barium study of the oesophagus in patients suspected of having a vascular ring or sling with stridor. In another sense, the initiation of such studies needs clinical insight, especially if there are no spinal anomalies, no obvious mass lesion on the anteroposterior chest radiograph, and no right aortic arch. $^{1-4}$ When compared with all infants with airways obstruction these 3 cases are rarities.

Choices of investigatory technique may not always be easy, but it is not a bad axiom to do the simple risk-free procedures first. Time-consuming studies, which may carry a distinctive risk, do not necessarily advance either diagnosis for the patient or management of the clinical problem. Among such studies may be included bronchoscopy, bronchography, angiography, and radioisotope ventilation perfusion studies. At best, studies of this type may delay definitive clinical management at a time that it is most needed. 


\section{References}

1 Stewart J R, Kincaid O W, Edwards J E. An atlas of vascular rings and related malformations of the aortic arch system. Springfield, I11: Thomas, 1964.

${ }^{2}$ Lincoln J C R, Deverall P B, Stark J, Aberdeen E, Waterston D J. Vascular anomalies compressing the oesophagus and trachea. Thorax 1969; 24: 295-306.

3 Caffey J. Pediatric $x$-ray diagnosis, seventh edition. Chicago: Year Book Medical Publishers, 1978.
4 Dunn J M, Gordon I, Chrispin A R, de Leval M R, Stark J. Early and late results of surgical correction of pulmonary artery sling. Ann Thorac Surg 1979; 28 : 230-8.

Correspondence to J Stark FRCS, Thoracic Unit, The Hospital for Sick Children, Gt Ormond Street, London WC1N 3JH.

Received 18 November 1982

\section{Fifty years ago}

\section{Nervousness in childhood \\ N B CAPON (Liverpool)}

Dr Capon gave a communication based on a series of nervous children seen in private practice and emphasised the importance of studying the child as a whole. He pointed out that insufficient attention seemed to be paid to the mental, intellectual, and spiritual aspects of childhood: paediatric physicians held a privileged position which should enable them to take a broad view. Careful physical examination must come first and this should include accurate determination of minor defects in sense organs. The key to the trouble was frequently found however, when the child's environment was investigated and the paediatric physician should have valuable observations to make upon important social problems-such as birth control, parental discord, divorce, educational methods.

Archives of Disease in Childhood 1933; 8: 365.

(This might almost have been written today. Norman Capon became professor of child health in Liverpool. PRE).

\section{The incidence of congenital syphilis D N NABARRO (London)}

Dr Nabarro said that it was impossible to form an accurate estimate of the incidence of congenital syphilis among the general population ... Figures varying between 0.6 and at least $10 \%$ have been given by different observers for the incidence of congenital syphilis among hospital patients. During the 17 years 1916-32 Dr Nabarro had studied 737 cases, including 32 parents. The average number of patients seen each year is 43 , so that the disease can hardly be regarded as negligible. Undoubtedly more cases would be detected by a wider application of the Wassermann and flocculation tests. He is of the opinion that untreated congenital syphilis, more particularly in a woman, may be transmitted to the offspring 'third generation syphilis'.

Archives of Disease in Childhood 1933; 8: 362.

(D N Nabarro established the laboratory service at Great Ormond Street and subsequently wrote a book, Congenital syphilis in 1954 which is probably still the best available account of the condition. He was a co-discoverer of the cause and mode of transmission of human trypanosomiasis. PRE). 